\title{
An introduction of accidents' classification based on their outcome control
}

\author{
Author(s) \\ Karanikas, Nektarios \\ DOI
}

10.1016/j.ssci.2014.09.006

Publication date

2015

Document Version

Submitted manuscript

Published in

Safety Science

Link to publication

Citation for published version (APA):

Karanikas, N. (2015). An introduction of accidents' classification based on their outcome control. Safety Science, 72(February), 182-189.

https://doi.org/10.1016/j.ssci.2014.09.006

It is not permitted to download or to forward/distribute the text or part of it without the consent of the author(s) and/or copyright holder(s), other than for strictly personal, individual use, unless the work is under an open content license (like Creative Commons).

\section{Disclaimer/Complaints regulations}

If you believe that digital publication of certain material infringes any of your rights or (privacy) interests,

please let the Library know, stating your reasons. In case of a legitimate complaint, the Library will make the material inaccessible and/or remove it from the website. Please contact the library:

https://www.amsterdamuas.com/library/contact/questions, or send a letter to: University Library (Library of the University of Amsterdam and Amsterdam University of Applied Sciences), Secretariat, Singel 425, 1012 WP Amsterdam, The Netherlands. You will be contacted as soon as possible. 


\section{An Introduction of Accidents' Classification Based on their}

\section{Outcome Control}

\section{Abstract}

Most safety oriented organizations have established their accidents classification taking into account the magnitude of the combined adverse outcomes on humans, assets and the environment without considering the accidents' potential and the actual attempts of the involved persons to intervene with the accident progress. The specific research exploited a large sample of an aviation organization accident records for an 11 years' time period and employed frequency and chi-square analyses to test a new accident classification scheme based on the distinction among the safety events with or without human intervention on the accident scene, indicating the management or not of their ultimate consequences. Furthermore, the research depicted the effectiveness of personnel strains to alleviate the accident potential outcomes and studied the contribution of time, local and complexity factors on the accident control attempt and the humans' positive or negative interference. The specific newly proposed accident classification successfully addressed the "controlled" or "uncontrolled" traits of the safety events studies, prior their severities consideration, and unveiled the effectiveness of personnel efforts to compensate for the adverse accident march. The portion between controlled and uncontrolled accidents in terms of the human intervention along with the effectiveness of the later may comprise a useful safety performance indicator that can be adopted by any industry sector and may be recommended through international and state safety related authorities.

Keywords: safety; performance; indicator; severity 


\section{Introduction}

In his work Geller (2001) supported that accidents do not inevitably result in actual injuries, and they are unusual and unexpected events. Therefore, an incident may also be classified as an accident if it embodies the potential for injury and damage, and accidents are caused and not just occurred due to present and insufficiently managed human, situational and environmental factors (e.g., improper use of tools and machines, inadequate use or provision of protective equipment, poor working conditions, improper maintenance, errors during procedures). Although ICAO (2013) highlights that there is practically no direct relation between the active failures and the type and extent of the adverse effects caused, safety cases' consequences comprise the basis for accidents' classification for most organizations and safety engaged authors.

Manuele (2003) noted that safety performance measurement in general is driven by incident recording and analysis. Bhagwati (2006) noticed that an accident might involve human injury and cost money, but an incident may cost money in the future; therefore a near-miss would be investigated as an accident although incidents are less visible than serious accidents, are not given sufficient attention, and they are not reported and recorded unless their damage cannot be hidden.

Bhagwati (2006) and Stranks (1994) stated that the direct and indirect consequences of the accidents involve victims and their family, colleagues and superiors, the workers morale, lost time due to injuries, treatment costs, training and time for workforce replacement, damages to infrastructure, need for replacement or repair of equipment, lost production time, spoiled materials, accident investigation time and downtime, loss of customers, adverse publicity etc. Under this concept, 
Stranks (1994) suggested the organizations should issue standard accident costing forms to facilitate the estimation of the aforementioned costs; these costs determine the accident severity classes developed by many organizations.

Davies et al. (2003) claimed that major accidents often look more complex than incidents only because organizations spend on the former more resources (e.g. larger investigation committees, more time). This is the reason Stranks (1994) proposed that the priority of investigations must be based on the accident types (e.g. machinery, chemical), the severity and the potential of damages and injuries, any increasing trend according to the organization's experience, the probability of legal implications, and the potential of insurance and financial claims. In addition, Manuele (2008) suggested that safety professionals shall focus on the "vital few" incidents that result in serious injuries and their investigation will lead to management actions towards the mitigation of their reoccurrence potential.

Bowen (2004) supported that an ideal strategy for measuring safety performance should combine frequency measures, severity indices, non-injury cases measurement, and safety success assessment through staff perceptions surveys. The combination of more than one measurement, such as frequency, severity (e.g., injuries) and activity measures (e.g., audits) were proposed by Peterson (2005) towards safety performance assessment.

The FAA (2000) presented the common safety performance requirements: quantitative requirements expressed as failure or accident rates, accident risk levels defined by the organization, and standardization requirements linked to the compliance to regulations. Martin \& Walters (2001) declared that metrics that are specific to the safety program under operation must be developed in order to measure 
performance and Galloway (2011) suggested the validation of measurement usability by questioning "What's in it for me?" The same author argued that, in the promotion of safety, there is a need for shifting from measuring the failure (e.g. accident rates) to the estimation of success; the goal of an organization might be not avoiding accidents but maintaining and increasing safety levels. Although the specific approach makes no difference in numbers since the success is literally the reciprocal of failure, such a view enhances positive organizational safety culture.

Easter et al. (2004) argued two discrete safety activities, the risk measurement and the risk subjective value, and related safety and health with a total loss control program, based on data from accident/incident investigation reports and cost analyses, and survey/inspection/audit reports.

As ICAO (2013) noticed personnel performance is unavoidable to fluctuate between the baseline and the ideal performance due to human variability and hazards' management during real operations. However, it must be noted that these same imperfect people make systems operate smoothly. Following a positive approach, Helmreich et al. (2001) argued that instead of emphasizing on human fallibility, organizations should consider the personnel's remarkable ability to compensate for their errors in the modern complex systems.

According to the FAA (2000) human performance may be measured quantitatively and qualitatively with time and accuracy parameters, the task safety and performance must have been determined in the system design stage and system performance is affected by operators' individual performance. As Gilbert (2008) appends, business survival and success is mostly relied on employees "who know what to do, know how to do it effectively and efficiently, and want to do it". 
Reason (1990) and ICAO (2013) presented the distinction between active failures ("what", "who" and "when"), referring to errors and violations as symptoms of safety problems that cause adverse effects, and latent conditions ("how" and "why"); the latter include managerial decisions related to the unsuccessful allocation of resources, line management fallible practices that may provoke error and violation producing conditions, and adverse workplace conditions.

In the scope of managing human error Roland \& Moriarty (1990) suggested that safety training shall include accident analysis and incident avoidance strategies, the installation of positive safety attitude, safety knowledge impartment, and hazard control enforcement. Also, in his comments on safety reward systems, McSween (2003) argued that the usual rewarding criteria do not encompass safety behaviours, whereas the focus on the individual or team safety performance, regardless of the fact that some candidates may have been lucky enough to avoid accidents / incidents although they were following unsafe practices and taking unwanted risks.

Taking into consideration the literature above, it seems that severity classes, even the distinction among accidents and incidents, dominate the contemporary accident rates computation in the scope of measuring safety performance, without, however, addressing the safety events' potential before calculating their adverse outcome magnitudes on the scope of defining their severity categories. Also, human attempts to control the accident progress towards the avoidance of more adverse implications are not considered. Following these remarks, the specific research exploited a large sample of accidents occurred in a large aviation organization and proposes a new accident classification scheme that accounts for the attempt to control the safety events' outcome prior the determination of its category according to the consequences provoked. 
Under this concept, the study considered that since some safety events may have resulted to specific adverse outcomes without any control on the side of the enduser, their severity classification may apply only for the safety events whose consequences comprise the outcome of a management attempt during the accident progress. The ultimate scope of the research is to propose the industry an innovative safety performance measurement based on accident severities control and human onscene intervention effectiveness and to provide organizations with an alternative decision tool for directing their safety investigations, training and potential reward schemes priorities and efforts.

\section{Methodology}

\subsection{General Framework}

The research was conducted in a large aviation organization that already monitors safety performance using accident rates according to their severity (accidents / 100.000 flying hours per accident severity class) and calculates their contributing factors percentages. One of the objectives of the research was to introduce safety performance indicators beyond the widely applied accident rates in order to assess the effectiveness of its safety program more substantially.

The specific aviation organization is divided into three (3) Sections (coded as F1, F2 and F3) with different roles. Each Section manages various types of aircraft spread in several operational Bases. The aircraft fleet is divided into two (2) generations $\left(2^{\text {nd }}\right.$ and $3^{\text {rd }}$ generation fleet) according to their age, all the Sections operating both aircraft generations fleet. The particular organization considers the fleet acquired prior year 1985 as $2^{\text {nd }}$ generation aircraft. 
More particularly:

- F1 performs the principal flying operations using seven (7) Bases (coded as F1B1, F1B2, F1Bx...) with five (5) aircraft types (coded as F1A1, F1A2, F1Ax....).

- F2 has a supportive role to the F1 operations (e.g. cargo flights for maintenance support, transportation of high management level staff and audit teams, emergency team transfers) and conducts operations from three (3) Bases (coded as F2B1, F2B2 and F2B3) with twelve (12) aircraft types (coded as F2A1, F2A2, F2Ax ....).

- F3 is the flight training section that manages two (2) Bases, coded as F3B1 and F3B2, and operates flights using four (4) aircraft types, coded as F3A1, F3A2, F3A3 and F3A4.

The organizations' accident severity is classified as either an A, B, C or D (Table 1) or an incident if it does not fit in the specific accident classes. 
P a g e | 8

\begin{tabular}{|c|c|c|c|c|}
\hline \multirow[t]{2}{*}{ IMPLICATIONS } & \multicolumn{4}{|c|}{ ACCIDENT CLASS } \\
\hline & $\mathrm{D}$ & $\mathrm{C}$ & B & A \\
\hline $\begin{array}{l}\text { Total Cost in Euros } \\
\text { (Including accident } \\
\text { damages on equipment, } \\
\text { environment and third } \\
\text { parties, as well the costs } \\
\text { for accident response, } \\
\text { accident investigation, } \\
\text { medical care etc.) }\end{array}$ & $\leq 20.000,00 €$ & $\begin{array}{l}>20.000,00 € \\
\leq 500.000,00 €\end{array}$ & $\begin{array}{l}>500.000,00 € \\
\leq 2.000 .000,00 €\end{array}$ & $\begin{array}{l}>2.000 .000,00 € \\
\text { Or total damage of } \\
\text { aircraft - } \\
\text { infrastructure } \\
\text { involved. }\end{array}$ \\
\hline Injuries & $\begin{array}{l}\text { Minor injuries } \\
\text { causing either the } \\
\text { need for part time } \\
\text { working, or } \\
\text { limitation in the } \\
\text { tasks assigned to, } \\
\text { or change of } \\
\text { tasks, or medical } \\
\text { care beyond first } \\
\text { aids provision. }\end{array}$ & $\begin{array}{l}\text { 1. Minor injury } \\
\text { causing absence } \\
\text { for more than } 1 \\
\text { day after the } \\
\text { accident day. } \\
2 . \text { Minor injury } \\
\text { causing the need } \\
\text { for permanent } \\
\text { change of job } \\
\text { specialty. }\end{array}$ & $\begin{array}{l}\text { 1. Major injury } \\
\text { or permanent } \\
\text { partial disability } \\
\text { caused. } \\
\text { 2. Hospital } \\
\text { admission } \\
\text { requirement for } \\
\text { more than3 } \\
\text { employees. }\end{array}$ & $\begin{array}{l}\text { Fatal injury or } \\
\text { permanent total } \\
\text { disability caused. }\end{array}$ \\
\hline
\end{tabular}

Table 1: Severity Accident Classification Used by the Aviation Organization under Study

Having discussed in the introduction section that there is actually no symmetry between causes and consequences since the same error may have completely different effects in a different context, the research explored the transition from the computation of safety events rates based on their classification according to their computed severity to an exploration of accidents and incidents outcome controlling attempt by the end users. On one side, such calculation would unveil which accident 
or incident estimated severities were a result of end-users intervention and, therefore, could be claimed as controlled, and which safety events results were matters of an uncontrolled state, hence, indicating an area of special focus requirement.

Under this framework, indicators for accidents with and without user intervention were tested in order to record the "control" of the accidents" progress or the "uncontrolled" factor. Additional indicators depicted the positive or the negative outcome of accidents with user intervention; the accidents whose consequences could not be controlled or worsened due to a "no other choice" condition were labelled as "neutral", although they include some human intervention at the accident scene. The $1^{\text {st }}$ and $2^{\text {nd }}$ columns of Table 2 present the recommended classification, alternative to the usual classifications based merely on accident severities. The classification presented was developed with the cooperation of three (3) safety experts of the organization under study in order to achieve clear, unambiguous and well understood formulations. Under this concept, following the distinction among controlled, uncontrolled and neutral type accidents, the severity categories of Table 1 would be considered only for the controlled and neutral accidents (e.g. accident or incident, "A" class aircraft accidents with user intervention). 


\begin{tabular}{|c|c|c|}
\hline $\begin{array}{ll}\text { ACCIDENT } & \text { CONTROL } \\
\text { CLASSIFICATION } & \end{array}$ & $\begin{array}{ll}\text { USER } & \text { REACTION } \\
\text { CLASSIFICATION } & \end{array}$ & EXAMPLES \\
\hline \multirow[t]{2}{*}{$\begin{array}{l}\text { CONTROLLED: The user } \\
\text { attempted to control the accident } \\
\text { march. }\end{array}$} & $\begin{array}{l}\text { POSITIVE: User's actions did not } \\
\text { worsen the outcome; the accident } \\
\text { outcome was managed successfully; } \\
\text { no errors or violations were noticed } \\
\text { during the control attempt. }\end{array}$ & $\begin{array}{l}\text { - Aviation: Safe landing after } \\
\text { engine flame out. } \\
\text { - Ground transportation: } \\
\text { Successful fire extinguishing } \\
\text { following } \\
\text { malfunction. }\end{array}$ \\
\hline & $\begin{array}{l}\text { NEGATIVE: User's actions } \\
\text { following the safety event initiation } \\
\text { resulted in adverse outcomes due to } \\
\text { human errors or violations. }\end{array}$ & $\begin{array}{l}\text { - Aviation: Incorrect technique } \\
\text { to recover the aircraft from } \\
\text { unstable state. } \\
\text { - Marine industry: Ineffective } \\
\text { ship manoeuvring to avoid } \\
\text { adverse sea conditions. }\end{array}$ \\
\hline $\begin{array}{l}\text { UNCONTROLLED: Safety event's } \\
\text { consequences were developed } \\
\text { without control; there had been no } \\
\text { intervention until the time the } \\
\text { outcomes were noticed. }\end{array}$ & NONE & $\begin{array}{l}\text { - Aviation: Important impacts on } \\
\text { the engine compressor blades } \\
\text { due to Foreign Object } \\
\text { Damages observed during } \\
\text { After Flight Inspection. } \\
\text { - Chemical industry: Blood } \\
\text { quality problems due to } \\
\text { exposure to hazardous } \\
\text { chemicals were identified after } \\
\text { periodical medical checks. }\end{array}$ \\
\hline $\begin{array}{l}\text { NEUTRAL: Inevitable application } \\
\text { of normal procedures; standard } \\
\text { reactions to identified problem. }\end{array}$ & $\begin{array}{l}\text { AS EXPECTED BY } \\
\text { PRESCRIBED PROCEDURES. }\end{array}$ & $\begin{array}{l}\text { Aviation: The tire blew out and } \\
\text { the pilot stopped the aircraft. } \\
\text { - Ground transportation: The } \\
\text { driver stopped the vehicle due } \\
\text { to engine oil light illumination. }\end{array}$ \\
\hline
\end{tabular}

Table 2: Proposed Accident Classification According to Control Attempt and Effectiveness of User Intervention 


\subsection{Sample and Classification Inter-rater Reliability}

The research exploited accident data for a period of 11 years, from 2000 to 2010, and totally 808 aircraft accident official reports were studied including accidents of all Table 1 severity categories. Each report was studied and, apart from the recording of the contributing factors that were formulated in each document, the researcher classified its accident according to the Table 2 scheme.

In order to test the reliability and the validity of the proposed classification $\left(1^{\text {st }}\right.$ column of Table 2), two (2) safety professionals who were not involved in the classification development were requested to classify individually a random sample of 150 accidents by applying the particular scheme. In order to assess their agreement Fleiss' Kappa statistical measure was employed (Fleiss, 1971); the initial computation resulted to a 0.74 value. The specific value, although is considered as a substantial agreement, was thought low on the scope of classifying accidents and consequently serving the need for potential organizations' emphasis on specific cases and the addressing of changes. Under this concept, the accident cases differently classified were discussed with the researcher and the two (2) aforementioned safety experts in order to identify potential confusion and misinterpretation of the classification model.

The problem identified was the somehow overlapping of the notions "standard reaction" and "attempt to control the accident" since the former in many cases was conceived by the ratters as a control attempt in the scope of avoiding further implications. In order to clarify these cases, a $3^{\text {rd }}$ column named 'EXAMPLES' was added in Table 2 as an illustration of the classification model. Following the aforementioned amendment, a different sample of 100 accidents were classified by 
the same professionals and a 0.91 Fleiss' Kappa value was calculated that comprises an almost perfect agreement.

Afterwards, the classification of human intervention for the controlled accidents was requested according to the $2^{\text {nd }}$ column of Table 2; Cohen's Kappa computations (Cohen, 1960) returned a value of 1 , meaning a perfect agreement. The ratters formulated that the examples provided in the $3^{\text {rd }}$ column of Table 2 were mostly helpful for the requested classification.

\subsection{Accident Factors Considered}

Although the aviation organization under study since 2011 has adopted the Human Factors Analysis and Classification System (HFACS), introduced by Shappell \& Weigmann (2003), the accident reports prior 2011 were based on the simple classification model referred in the next paragraph. Since the main scope of the current research was to introduce an accident classification according to its control attempt, and taking into account that the re-classification of the 808 accidents with the HFACS model would require the exploration of the evidence for each safety event and consequently a very high amount of time, the study followed the predetermined simple classification found in the reports.

The accident factors that were considered by the aviation organization under research until 2011 were (in alphabetical order):

- $\quad$ Bird strikes

- Domestic Objects Damages (DOD)

- Flight Supervision

- Foreign Objects Damages, excluding Bird Strikes (FOD) 
- Maintenance personnel acts

- Material failures excluding DOD's

- No cause identified

- Other factors (e.g., weather)

- Outsource - depot maintenance acts

- User - crew acts

It is hereby clarified that the acts and supervision factors included both errors and violations.

\subsection{Data Analysis}

The data collected and recorded was analysed as follows:

1. Frequency analysis of the controlled, uncontrolled and neutral accident classes as a safety performance indicator of accidents' progress control attempt.

2. Frequency analysis of the controlled accidents according to their positive or negative result as an indicator of human intervention effectiveness.

3. Frequency analysis of the severity classes (A, B, C and D) for the controlled accidents, as a more realistic indicator of organizational safety performance since safety shall be based principally on the control of events.

4. Chi-square statistics of the accident factors mentioned in paragraph 2.3 above regarding controlled, uncontrolled and neutral accidents in order to explore any difference in the effects of the contributing factors; the statistical significance level was set to 0.05 . The following cases were also considered:

- The user and supervision factors were attributed as contributors in every Foreign Object Damage accident (indicated by User acts and General 
Supervision titles correspondingly in the results section), excluding bird strikes far from the airport. The particular decision was based on the fact that the presence of any object in the areas of aircraft movements in the majority of the cases is a matter of negligence on behalf of the employees, both the endusers and the supervisors.

- The crew, maintenance and supervision personnel acts factors were additionally consolidated in one factor named Human Performance in order to illustrate its total contribution to accidents. If human performance had been involved in the "other causes" and "bird strikes" factors, the end-user factor was also recorded as Human Performance factor.

5. Exploration of any relations regarding the entities calculated in the paragraphs 1,2 and 3 above as dependent variables with the independent variables of Table 3 on the scope of revealing any temporal (year, month, date) and systemic / local related effects (aircraft type and generation, Base size and identity, Section) to be managed in the frame of the changes to be addressed in the safety program of the organization under research. The "Base size" variable was introduced as an indicator of complexity; under this concept the Bases were classified as " $\mathrm{A}$ " (large ones with more than 500 employees) and "B" (smaller ones with less than 500 employees). Chi-square tests were employed for the specific analyses, with a significance level of 0.05 ; in order to ensure the validity of the tests, any cases with population less than five (5) were excluded from the computations. 


\begin{tabular}{|l|l|}
\hline INDEPENDENT VARIABLES & $\begin{array}{l}\text { DEPENDED VARIABLES } \\
\text { (the numbers refer to the } \\
\text { paragraphs above })\end{array}$ \\
\hline Year of the accident & 1,2 \\
\hline Month of the accident & 1,2 \\
\hline Day of the accident & 1,2 \\
\hline Aircraft type & 1,2 \\
\hline Aircraft generation & $1,2,3$ \\
\hline Base accountable for the accident & $1,2,3$ \\
\hline Size of the Base accountable for the accident & $1,2,3$ \\
\hline Section that the Base reports to & $1,2,3$ \\
\hline
\end{tabular}

Table 3: Independent and Depended Variables for Statistical Computations

\section{Results}

\section{Accident Outcome Control}

- The distinction of the accidents based on the controlling attempt of their outcome resulted to the percentages of $43.3 \%$ controlled accidents, $43.7 \%$ uncontrolled accidents and 13\% neutral accidents. Therefore, the neutral accidents excluded, half of the accidents were attributed as uncontrolled, meaning that their severity was not a matter of users' intervention.

- The "controlled" class accidents concerned, $87.2 \%$ of them had a positive outcome and the rest $12.8 \%$ resulted to more adverse impacts than expected due to human error or violation, the results indicating a high positive human intervention in this accident type. 
- The severity of the controlled accidents is graphically drawn in Figure 1;4.3\% of these accidents resulted to high severity (A class), in $1.4 \%$ of the cases the accident severity was "B", the majority of the accidents exhibited medium severity " $C$ " $(64.1 \%)$ and the rest $30.2 \%$ of the accidents resulted to low severity outcomes. The high severity accident percentages ("A" and "B" classes) were almost identical if all accidents would be considered regardless their outcome control; the " $\mathrm{C}$ " class percentage for total accidents was calculated to $55.4 \%$ (about 10\% less than in controlled accidents) and " $\mathrm{D}$ " class ones presented a percentage of $39.4 \%$ (about $9 \%$ more compared to controlled accidents).

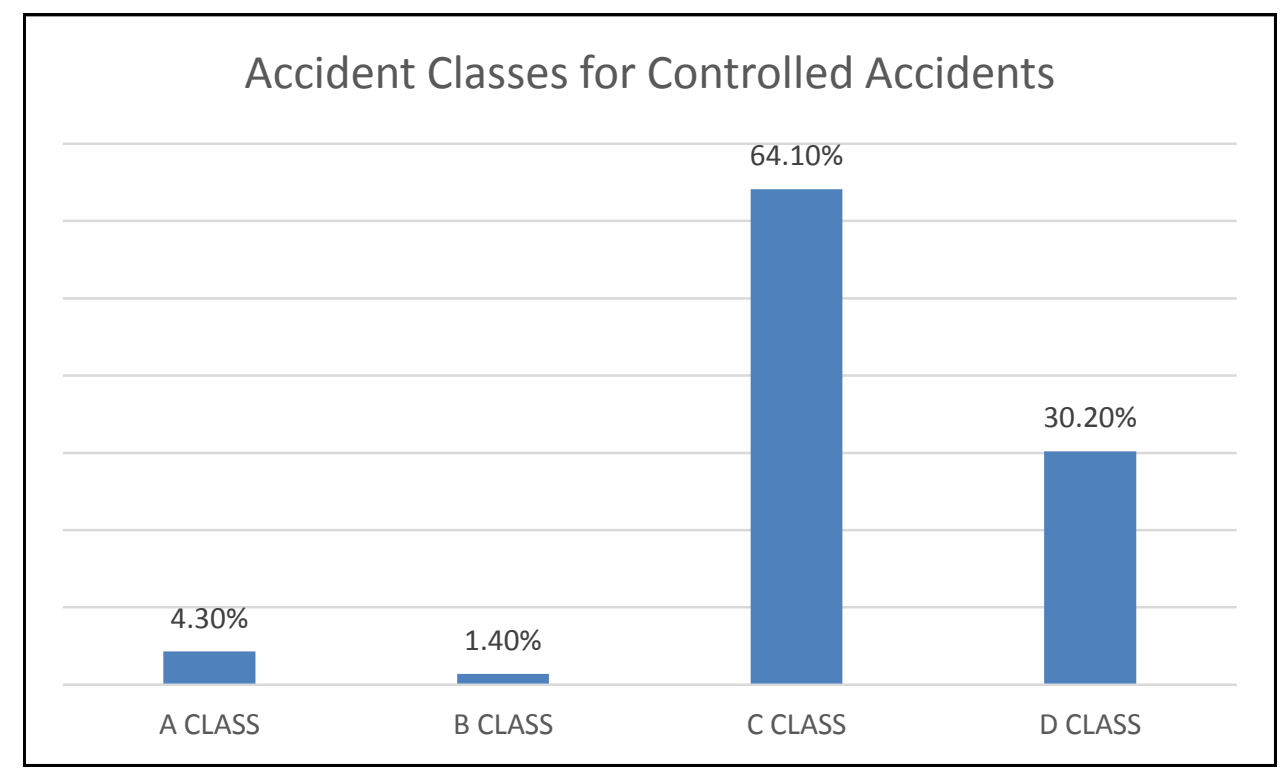

Figure 1: Percentages of Controlled Accidents' Severities

\section{Contributing Factors}

The contribution of the factors that were found significantly different according to the accident control classification, as derived by the Chi-square tests, are presented in Table 4; depot maintenance factors and "other" factors did not affect the accidents' controllability. 


\begin{tabular}{|c|c|c|c|c|c|}
\hline & Acciden & type & & & Significance \\
\hline Accident factor & $\begin{array}{l}\text { Neutral } \\
(\%)\end{array}$ & $\begin{array}{l}\text { Uncontrolled } \\
(\%)\end{array}$ & $\begin{array}{l}\text { Controlled } \\
(\%)\end{array}$ & $\begin{array}{l}\text { Chi- } \\
\text { square } \\
\text { value }\end{array}$ & \\
\hline Material failures & 15.3 & 27.6 & 57.1 & 62.497 & 0.000 \\
\hline Bird strikes & 2.6 & 72.4 & 25.0 & 29.179 & 0.000 \\
\hline $\begin{array}{l}\text { Foreign Object } \\
\text { Damages (FOD) }\end{array}$ & 5.1 & 77.8 & 17.2 & 53.224 & 0.000 \\
\hline $\begin{array}{l}\text { Domestic Object } \\
\text { Damages (DOD) }\end{array}$ & 8.2 & 59.0 & 32.8 & 6.389 & 0.040 \\
\hline Crew acts & 16.8 & 36.4 & 46.7 & 6.305 & 0.042 \\
\hline User acts & 12.5 & 50.7 & 36.8 & 9.117 & 0.011 \\
\hline $\begin{array}{l}\text { Maintenance } \\
\text { staff acts }\end{array}$ & 10.9 & 58.1 & 31.0 & 13.223 & 0.001 \\
\hline $\begin{array}{l}\text { Flights } \\
\text { Supervision }\end{array}$ & 6.4 & 55.3 & 38.3 & 7.457 & 0.023 \\
\hline $\begin{array}{l}\text { General } \\
\text { Supervision }\end{array}$ & 5.3 & 66.5 & 28.2 & 53.073 & 0.000 \\
\hline $\begin{array}{l}\text { Human } \\
\text { performance }\end{array}$ & 12.2 & 52.0 & 35.8 & 20.608 & 0.000 \\
\hline
\end{tabular}

Table 4: Chi-square Results - Effects of Accident Factors on Accident Outcome Control 


\section{$\underline{\text { Temporal Variables }}$}

The Chi-square tests indicated no difference of the accidents' control attempts (controlled, uncontrolled and neutral accidents) and the outcome (positive or negative) of the controlled accidents along the years, the months and the weekdays.

\section{$\underline{\text { Aircraft Type variable }}$}

- The Chi-square tests showed that the aircraft type affects the accidents' controllability attempt significantly $\left[\chi^{2}(13, N=652)=75.047, p=0.000\right]$; F1A2, F2A2 and F3A4 aircraft types were involved in the most uncontrolled accidents, whereas F2A8 and F2A10 aircraft types were involved in the most controlled ones.

- Among the aircraft types that were involved in controllable accidents, F2A6 aircraft was attributed a $100 \%$ positive outcome, whereas F1A1 and F1A2 types were involved in the most adverse outcome accidents $\left\{\right.$ Chi-square: $\left[\chi^{2}(9, N=303)\right.$ $=19.249, p=0.023]\}$.

\section{$\underline{\text { Aircraft Generation variable }}$}

- The aircraft generation differentiates the controllability of the accidents as Chisquare tests resulted $\left[\chi^{2}(2, N=810)=32.003, p=0.000\right] ; 3^{\text {rd }}$ generation aircraft seem to be involved in more uncontrolled accidents, as illustrated in Figure 2. 


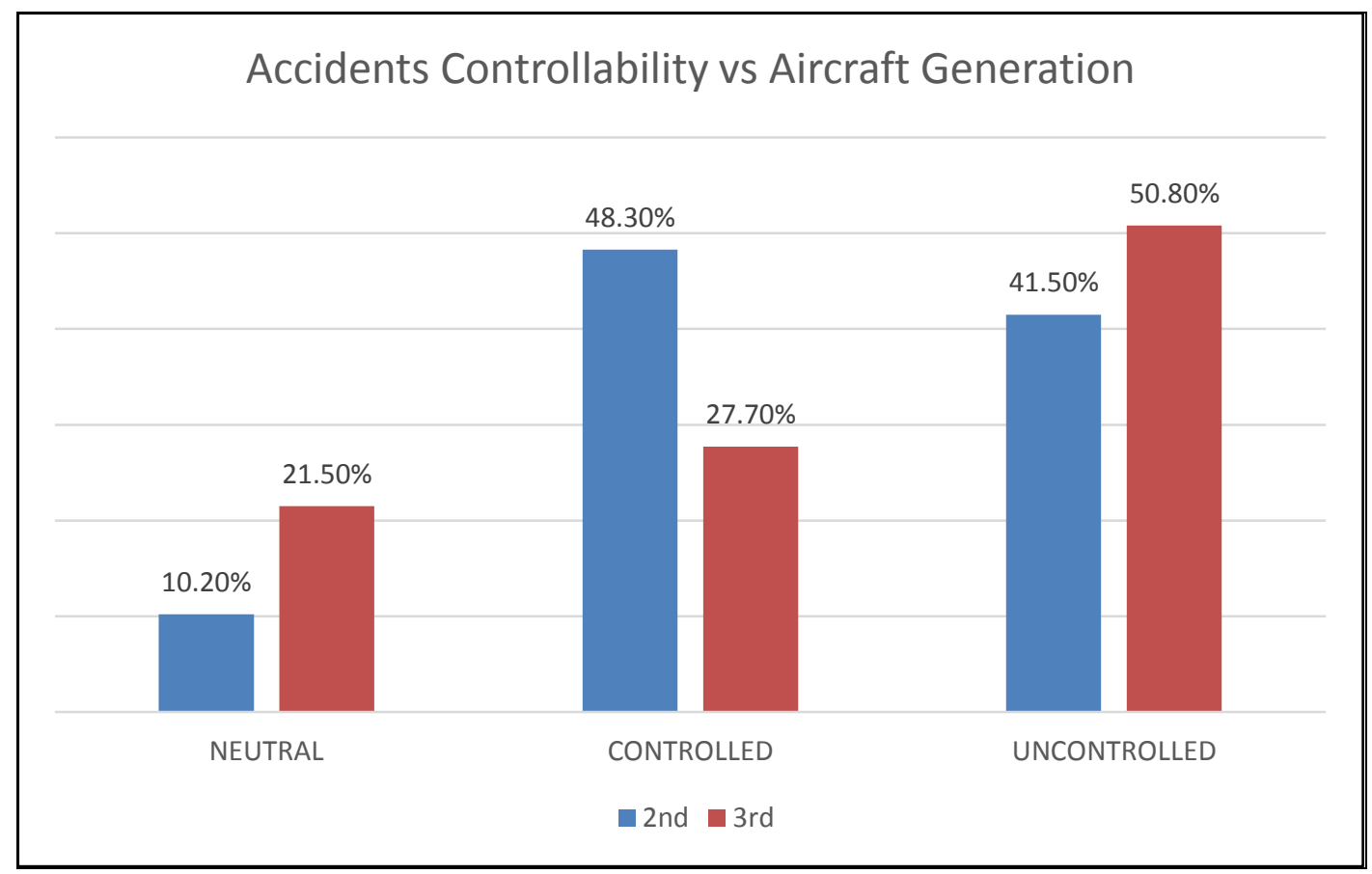

Figure 2: Aircraft Generation Effects on Accidents' Controllability

- $2^{\text {nd }}$ generation aircraft differ significantly from $3^{\text {rd }}$ generation ones regarding the outcomes of controlled accidents, as pictured in Figure 3 \{Chi-square: $\left[\chi^{2}(1, N=\right.$ $351)=16.133, p=0.000]\}$; the former demonstrate a much higher percentage of positive outcome.

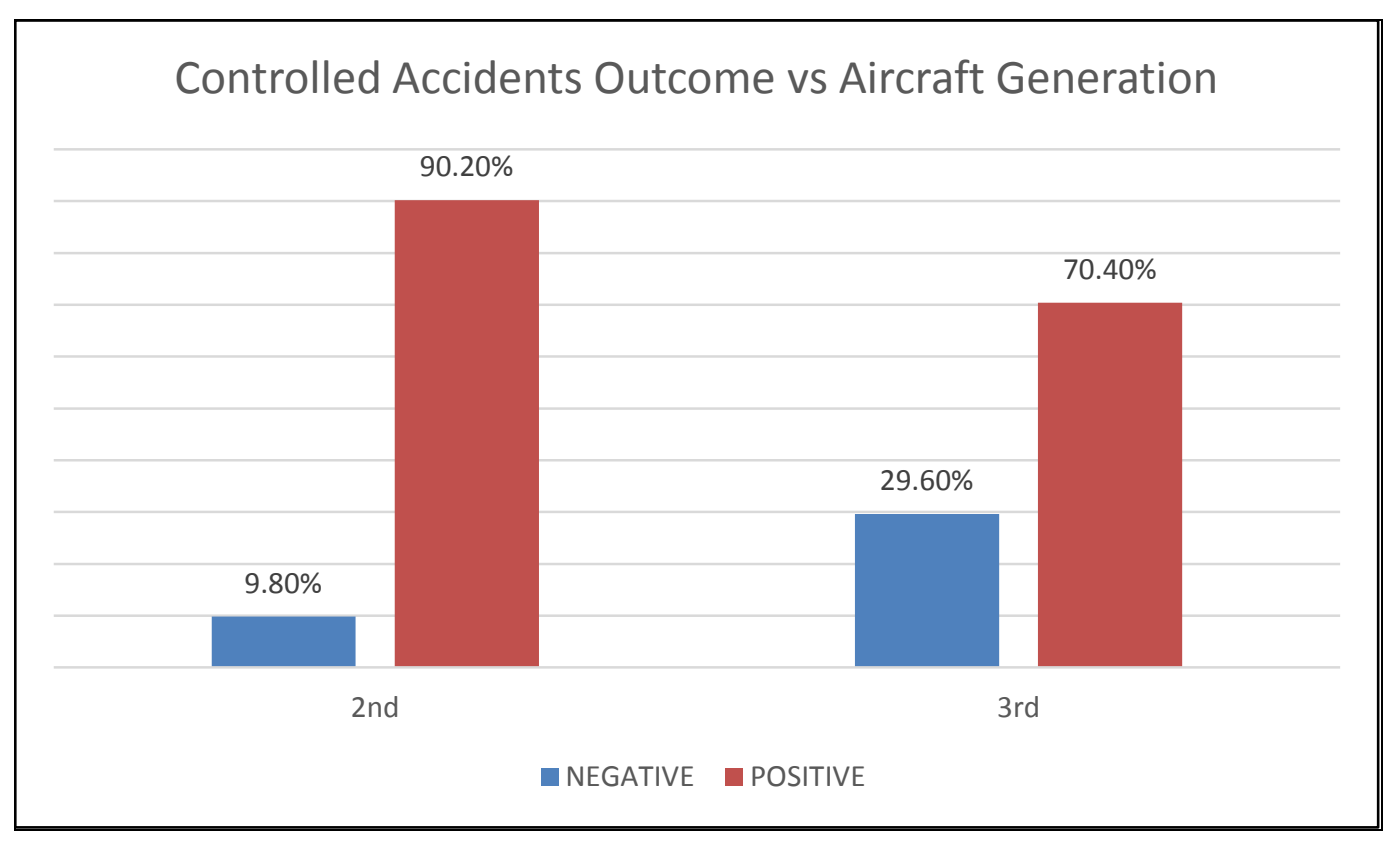

Figure 3: Aircraft Generation Effects on Controlled Accidents' Outcome 
- The controlled accident's severity was affected by the aircraft' generation, as indicated by the Chi-square test $\left[\chi^{2}(1, N=351)=16.133, p=0.000\right]$; As shown in Figure $4,3^{\text {rd }}$ generation aircraft are involved in more " $A$ " and " $B$ " class accidents, whereas $2^{\text {nd }}$ generation aircraft are involved in " $C$ " class accidents.

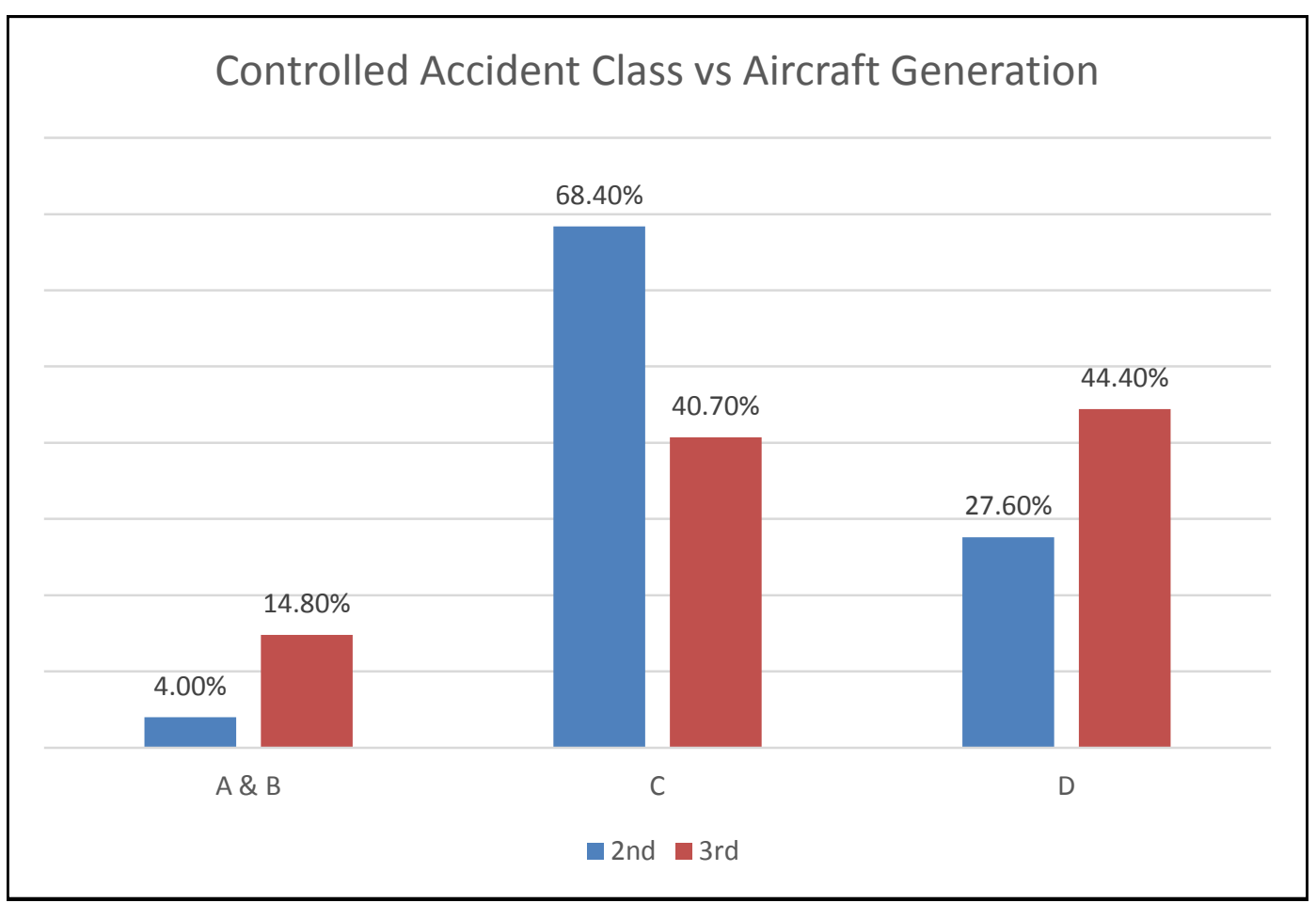

Figure 4: Aircraft Generation Effects on Controlled Accident Severity

$\underline{\text { Base Variable }}$

- The controllability of the accidents was affected by the Bases involved \{Chisquare: $\left.\left[\chi^{2}(20, N=799)=67.188, p=0.000\right]\right\} ; \mathrm{F} 2 \mathrm{~B} 3$ and F2B2 Bases appeared with the most cases of controlled aircraft accidents, whereas F1B2 and F1B4 Bases had the most uncontrolled ones.

- Chi-square tests showed that there is an effect of the Base on the accident outcome for controlled cases $\left[\chi^{2}(8, N=329)=18.061, p=0.022\right]$; F1B6 and F3B1 were involved in more controlled accidents with positive outcome whereas F1B1 and F2B3 appeared with higher frequencies of negative outcomes. 
- Among the Bases with controlled accidents, F1B3 and F1B5 ones experienced more severe accidents $\left\{\right.$ Chi-square: $\left.\left[\chi^{2}(12, N=303)=32.864, p=0.001\right]\right\}$.

\section{$\underline{\text { Base Size }}$}

- Chi-square tests showed that the accidents controllability is affected by the Base size $\left[\chi^{2}(2, N=806)=6.467, p=0.039\right]$; more complex "A" size Bases experienced more uncontrolled accidents than the "B" size ones as illustrated in Figure 5.

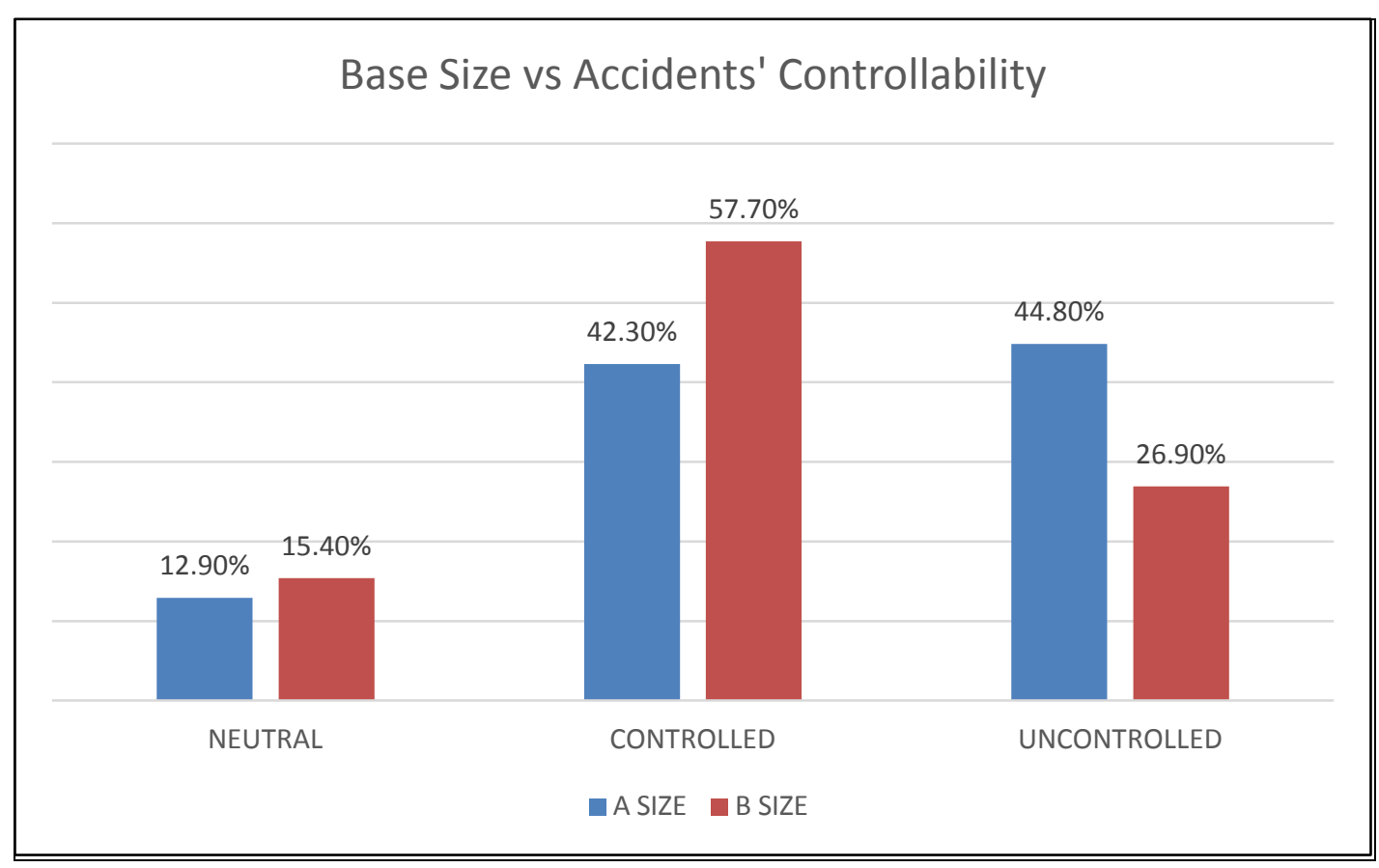

Figure 5: Base Size Effects on Accident Controllability

- The outcome of the controlled accidents is more frequently positive for " $\mathrm{A}$ " size Bases $\{$ Chi-square: $[\chi 2(1, \mathrm{~N}=349)=5.888, \mathrm{p}=0.023]\}$.

- According to the Chi-square tests the accident class for controlled safety events is not affected by the Base size. 


\section{$\underline{\text { Section Variable }}$}

- The controllability of the accidents depends on the Section involved as derived by the Chi-square tests $\left[\chi^{2}(4, N=810)=45.866, p=0.000\right]$. As noticed in Figure 6, F1 has the most uncontrolled accidents, whereas F2 is involved in the most controlled ones.

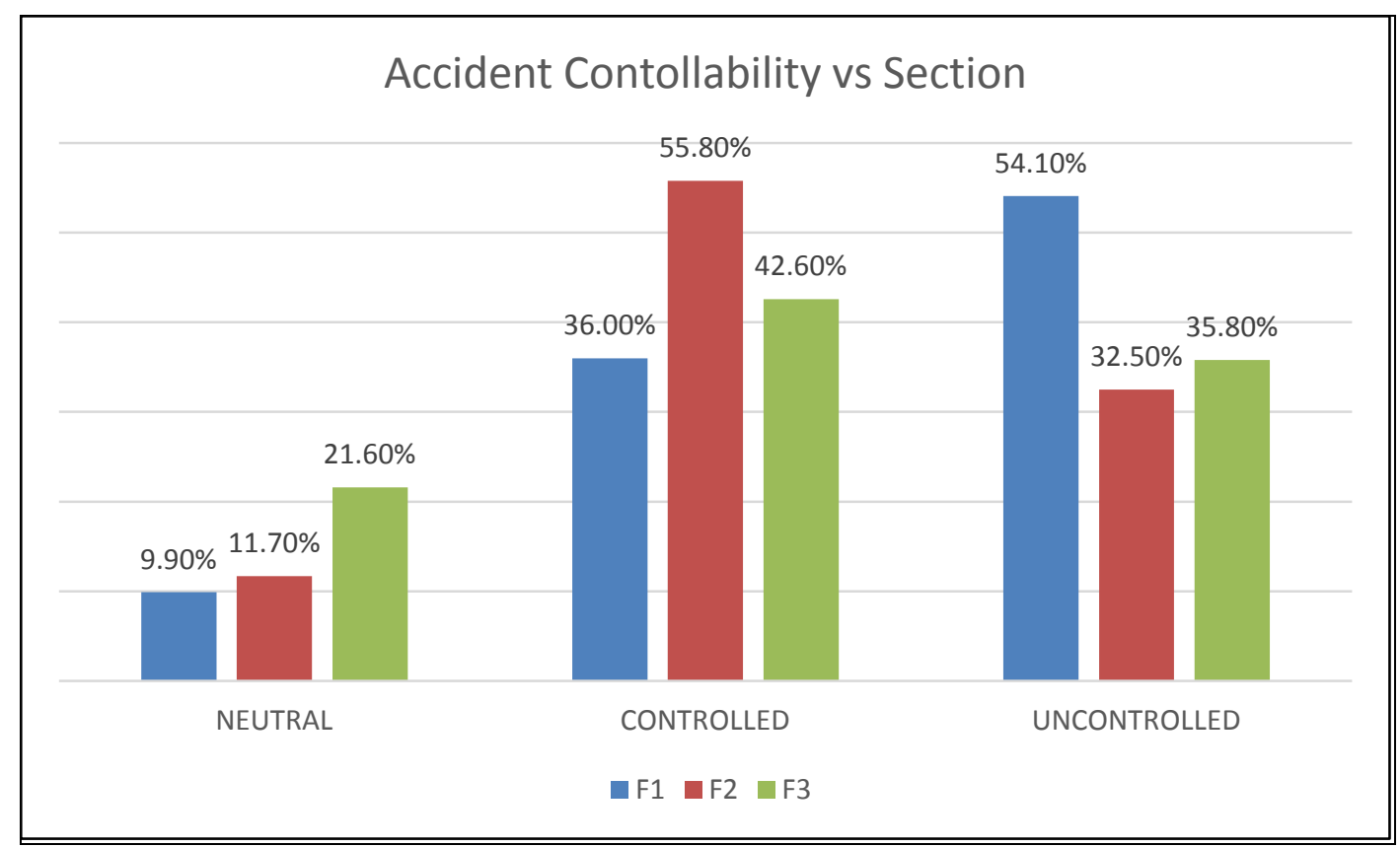

\section{Figure 6: Section Variable Effects on Accidents' Controllability}

- The outcome of the controlled accidents was not affected by the Section variable (Chi-square test).

- Chi-square tests indicated that the accidents' severity for the controlled safety cases was affected by the Section involved $\left[\chi^{2}(4, N=351)=31.678, p=0.000\right]$ as pictured in Figure 7; F1 appears with the most severe accidents ("A" \& "B" class) and the least " $\mathrm{D}$ " class cases, whereas F2 is involved in the most average severity class accidents ("C"). It shall be noticed that no high severity controlled accident was recorded for F3 Section. 


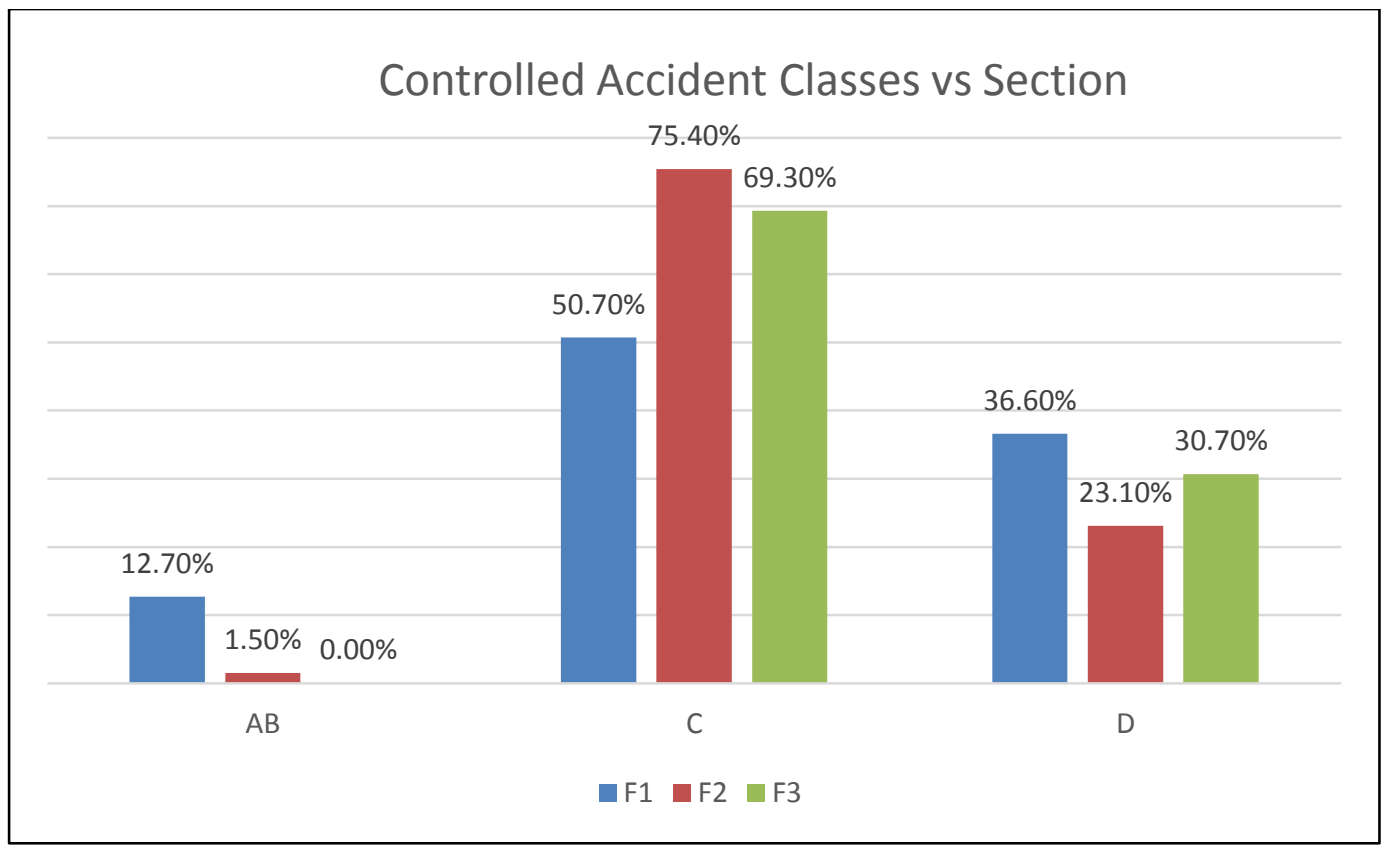

Figure 7: Section Variable Effects on Controlled Accidents' Severity

\section{Discussion}

Taking into consideration the results of the controlled, uncontrolled and neutral category accidents ratios, it is apparent that, the neutral accidents excluded, the specific organization's accident outcomes are half depended on 'luck' and half caused by its employees' attempts to control the situations on the accident scene. At a first glance it is claimed that there must be must effort on reducing the uncontrolled accidents by focusing on their contributing factors. Nevertheless, it must be highlighted that the large percentage of positive outcomes for the controlled accidents $(87,2 \%)$ reveals the considerably high effectiveness of its personnel acts when they dealt with the accident progress, indicating in these cases a remarkable awareness and discipline of the human involved regarding the control of the accident severity.

Although the frequency of " $A$ " and "B" severity categories for the accidents controlled was similar to the ones if total accidents were considered, a $10 \%$ percent difference was computed for the "C" class (higher percentage for controlled 
accidents) and "D" class (lower percentage for controlled accidents). Thus, the organization's current computation of the accident class percentages and rates regardless their outcome controlling attempt provides a rather misguiding impression of fewer medium severity " $C$ " class accidents and more low severity " $D$ " class ones, potentially misleading its safety program initiatives.

Ten (10) out of twelve (12) factors that affect the accident's controllability dominated the uncontrolled accidents. Bird Strike, Foreign Object Damages and Domestic Object Damages factors may be considered sensible to contribute more in uncontrolled accidents than in controlled ones since the time of any object detachment (DOD) or strike (Bird strike - FOD) on the aircraft and especially on the engine cannot be predicted along with its path and impacts' size and depth. The human acts concerned, maintenance staff acts and general supervision factors demonstrated the highest rates for the uncontrolled cases, indicating areas that require special treatment. On the other side, air crew acts resulted to more controlled accidents along with the contribution of unexpected failures (e.g., leaks, wreckage) that probably were confronted more determinatively by the crew members.

The results regarding the aircraft types revealed areas of potential attention regarding the crew and ground staff training and awareness and the corresponding maintenance policy (material failures and Domestic Object Damages), factors that actually differ between various aircraft types. The rest causes (Bird strikes, Foreign Object Damages and Supervision) are managed mostly in a common way and do not depend on aircraft models. It must be noted that each of the three Sections operates each of the types most frequently involved in uncontrolled accidents, whereas both aircraft types mostly involved in controlled accidents operate in Section F2. 
Moreover, F2A6 aircraft type that is involved in $100 \%$ effective human interventions may be seen as a positive example regarding the aforementioned factors which diversify among aircraft types. On the opposite side, the organization shall emphasize in these factors for the personnel operating F1A1 and F1A2 aircraft models, which exhibited the highest records in the negative outcomes during accident progress controlling attempts.

Also, it is of great interest that relatively new age aircraft fleet $\left(3^{\text {rd }}\right.$ generation) demonstrates higher percentages in the uncontrolled accidents, higher accident severities for the controlled accidents and more negative effects during users' intervention for the controlled accidents. This may indicate that although $2^{\text {nd }}$ generation aircraft usually are equipped with less automation and their users operate less modern means during their ground and flight operations (radars, maintenance devices etc.) and training (e.g., flight and maintenance simulators) compared to $3^{\text {rd }}$ generation ones, they present a better safety performance in terms of accident outcome control.

Furthermore, large and more complex Bases in terms of operations and personnel management were computed with more uncontrolled accidents; however, they demonstrated a better user's performance for the controlled accidents. Eventually, taking into account the results of Base and Sections variables, it may be claimed that the Section F1 and its subordinate Bases are noticeably involved in more uncontrolled accidents, in the majority of the cases related to ineffective human intervention, and in high severity controlled accidents. On the opposite side the F2 Section and its Bases demonstrated a better performance in the accident outcomes 
controllability and in the cases where users attempted to control the accident progress, and they were involved in more medium and low severity accidents.

\section{Conclusions}

Taking into consideration the results of the current research and in accordance with the methodology applied regarding the alternative accident classification on the basis of the accident's control by the user instead of its mere severity class, it is claimed that the classification scheme of Table 2 may comprise a more realistic method for measuring organizational safety performance prior considering accident severities.

The suggested classification can be appropriately adapted by any organization that seeks to unveil if its accident severities are a matter of control or a result of pure "luck", to depict the effectiveness of its employee's interventions on the accident scene, and to explore the influence of accident factors and other systemic variables on the accidents' controllability and user actions' outcomes.

Although the research was conducted using accident data of an aviation organization, the proposed classification is not restricted to the aviation industry and may be effectively adopted by every industry sector that seeks a substantial measurement of its actual safety performance by assessing the ratios of "controlled" and "uncontrolled" cases regarding its accident consequences and the human intervention success on the accident scene. The ultimate target of safety must be the increase of both the controlled accidents and the effectiveness of human acts during the accident march. 
Following the suggested classification, the organizations may proceed further to the exploration of the factors affecting their controlled and uncontrolled accidents as demonstrated in the current study, and, therefore, may drive their initiatives and efforts in a more effective way under the resource constraints inevitably present in every business. Safety investigations, training, audits, rewarding policy and any other safety program components may be better planned and implemented taking into consideration the strongest and the most vulnerable parts of the organization.

Finally, beyond the application of such classification by individual organizations, the proposed scheme may constitute a basis for a common agreed benchmarking measurement among safety oriented organizations and stimuli for the introduction of a similar scheme to international and state standards and regulations regarding safety performance indicators.

\section{References}

Bhagwati, K. (2006). Managing Safety. NJ: Wiley - VCH.

Bowen, B. D. (2004). 'Developing a Standarized Mechanism for Measuring airline Service Performance: A Preparation for Airlines \& the Flying Public', International Journal of Applied Aviation Studies, 4 (2), pp. 39-62.

Cohen, J. (1960). 'A Coefficient of Agreement for Nominal Scales', Educational and Psychological Measurement, 20 (1), pp. 37-46.

Davies, J., Ross, A., Wallace, B. \& Wright, L. (2003). Safety Management: A Qualitative Systems Approach. UK: Taylor \& Francis. 
Easter, K., Hegney, R. \& Taylor, G. (2004). Enhancing Occupational Safety \& Health. UK: Butterworth - Heinemann.

Fleiss, J. (1971). 'Measuring Nominal Scale Agreement Among Many Raters'. Psychological Bulletin, Vol. 76 (5), pp. 378-382.

Galloway, S. M. (2011). 'Safety Measurement: The Dysfunctional Big Picture', Managing Safety, October 2001, pp.28-30.

Geller, E. S. (2001). The Psychology of Safety Handbook. ( $2^{\text {nd }}$ ed.). UK: Lewis Publishers.

Gilbert, R. (2008). A Quick Guide to Health \& Safety. UK: Woodhead Publishing Ltd.

Helmreich, B., Maurino, D. \& Reason, J. (2001). 'Heroic Compensations: The Benign Face of the Human Factor', Flight Safety Australia, January - February 2001, pp. 28-31.

International Civil Aviation Organization (ICAO). (2013). Safety Management Manual Doc. 9859. CA.

Manuele, F. A. (2003). On the Practice of Safety. NJ: John Wiley \& Sons.

Manuele, F. A. (2008). Advanced Safety Management Focusing on Z10 \& Serious Injury Prevention. NJ: John Wiley \& Sons.

Martin, W. F. \& Walters, J. B. (2001). Safety \& Health Essentials for Small Businesses. MA: Butterworth - Heinemann.

McSween, T. E. (2003). Value-Based Safety Process. NJ: John Wiley \& Sons.

Peterson, D. (2005). 'Setting Goals, Measuring Performance', Professional Safety, December 2005, pp. 43-48. 
Reason, J. (1990). 'The Contribution of Latent Human Failures to the Breakdown of Complex Systems', Philosophical Transactions of the Royal Society of London, Series B, Biological Sciences, 327 (241), pp. 475-484.

Roland, H. E. \& Moriarty, B. (1990). System Safety Engineering \& Management. NY: Wiley \& Sons.

Shappell, S. \& Weigmann, D. (2003). A Human Error Approach to Aviation Accident Analysis - The Human Factors Analysis and Classification System. UK: Ashgate Publishing.

Stranks, J. (1994). Management Systems for Safety. UK: Pearson Education.

US Federal Aviation Administration (FAA). (2000). System Safety Handbook. WA. 